being living autogenous tissue. Hence the potential for growth exists when the pulmonary autograft is used in the aortic position, and that is the reason the Ross operation is considered ideal for aortic valve replacements in infants and children. However, the potential for growth is lost when the pulmonary autograft is used in the mitral position because it has to be housed within the Dacron tube. On the other hand, inasmuch as the autograft is lying in the left atrium as a top hat, a partial or total preservation of the mitral valve apparatus is feasible, as was done in our patient. The autograft is a living autogenous tissue, fully flexible, and it cannot obstruct the left ventricular outflow tract because of its position inside the left atrium (Figs 1 and 2).

The improved clinical condition of our patient, freedom from anticoagulation, absence of thromboembolism, and the maintained excellent performance of the pulmonary autograft in the mitral position 6 years later cautiously support this procedure as a viable alternative in specific clinical situations requiring replacement of the mitral valve. However, a larger number of patients is needed with longer follow-up periods before one can confidently advocate this procedure. Inasmuch as it is another innovation from a pioneer surgeon, we suggest calling this procedure the Ross II procedure.

\section{REFERENCES}

1. Yacoub MH, Kittle CF. A new technique for replacement of the mitral valve by a semilunar valve homograft. J Thorac Cardiovasc Surg 1969;58:859-69.

2. Ross D, Jackson M, Davies J. The pulmonary autograft-a permanent aortic valve. Eur J Cardiothorac Surg 1992;6:113-7.

3. Kumar N, Prabhakar G, Gometza B, Al Halees Z, Duran CMG. The Ross procedure in a young rheumatic population: early clinical and echocardiographic profile. J Heart Valve Dis 1993;2:3769.

4. Ross DN. Replacement of aortic and mitral valves with a pulmonary autograft. Lancet 1967;2(523):956-8.

5. Ross DN, Kabbani S. Mitral valve replacement with a pulmonary autograft: the mitral top hat. J Heart Valve Dis 1997;6: 542-5.

\title{
PARTIAL LEFT VENTRICULECTOMY IN AN INFANT WITH DILATED CARDIOMYOPATHY
}

\author{
Shinpei Yoshii, MD, ${ }^{a}$ Shigeru Hosaka, MD, ${ }^{a}$ Wataru Takahashi, MD, ${ }^{\text {a }}$ Hiroshi Amano, MD, ${ }^{\text {a }}$ Samuel J. K. Abraham, MD, \\ Shigeaki Kaga, MD, ${ }^{a}$ Yusuke Tada, MD, ${ }^{a}$ Hisashi Sugiyama, MD, ${ }^{\mathbf{b}}$ and Jun Yanai, MD, ${ }^{\mathbf{b}}$ Yamanashi, Japan
}

Partial left ventriculectomy for dilated cardiomyopathy (DCM) was first reported by Batista and associates ${ }^{1}$ in 1996. Several authors have reported their clinical experience with this operation in adults. ${ }^{1-3}$ However, its use in infants has not been reported. We have performed partial left ventriculectomy in an infant with DCM.

Clinical summary. A 5-month-old girl was admitted on an emergency basis with symptoms of severe congestive heart failure. The cardiothoracic ratio (CTR) on chest radiography was $67 \%$. Echocardiography revealed left ventricular dilatation and a thin myocardium. At the apex, sponge-like myocardium ${ }^{4}$ was detected. The diastolic dimension was 44.5 $\mathrm{mm}$, the systolic dimension was $42.4 \mathrm{~mm}$, and the ejection fraction was $13.5 \%$. The patient was treated with dopamine, amrinone, and furosemide, and her condition stabilized. The CTR was reduced from $67 \%$ to $63 \%$.

From the Departments of Surgery ${ }^{\mathrm{a}}$ and Pediatrics, ${ }^{\mathrm{b}}$ Yamanashi Medical University, Yamanashi, Japan.

Received for publication Oct 19, 1998; accepted for publication Nov 2, 1998.

Address for reprints: Shinpei Yoshii, MD, Yamanashi Medical University, Tamaho-Cho, Nakakoma-Gun, Yamanashi, 409-3898, Japan.

J Thorac Cardiovasc Surg 1999;117:616-8

Copyright $\odot 1999$ by Mosby, Inc.

$0022-5223 / 99 \$ 8.00+0 \quad 12 / 54 / 95591$
Laboratory investigation revealed no signs of acute myocarditis. Cardiac catheterization showed normal coronary arterial anatomy. Myocardial biopsy revealed no abnormalities. The diagnosis of DCM was made, and conventional treatment was started.

Echocardiography and chest cardiography 2 months later revealed an increase in the diameter of the left ventricle and a decrease in the ejection fraction. Her general condition was deteriorating. Growth hormone therapy ${ }^{5}$ was started. Mitral regurgitation and left ventricular enlargement (diastolic dimension, $51.3 \mathrm{~mm}$; systolic dimension, $49.5 \mathrm{~mm}$; ejection fraction, $7.4 \%$ ) were detected by echocardiography 2 weeks later, at which time she became seriously ill. The CTR increased to $67 \%$ (Fig 1). Reduced urine volume, elevated hepatic transaminase concentrations, and metabolic acidosis also were detected. Emergency partial left ventriculectomy was carried out. The 8-month-old patient weighed $5.2 \mathrm{~kg}$. Using cardiopulmonary bypass and cardioplegic arrest, a partial left ventriculectomy and mitral valvuloplasty with Alfieri repair ${ }^{3}$ were performed. Transesophageal echocardiography and continuous monitoring of mixed venous oxygen saturation $\left(\mathrm{SvO}_{2}\right)$ with a thermodilution cannula were used. The inner wall of the apex of the left ventricle contained sponge-like coarse trabeculations. The posterior left ventricular muscle between the two papillary muscles was resected as much as possible, especially at the apex. Weaning from cardiopulmonary bypass was smooth. No mitral regurgita- 

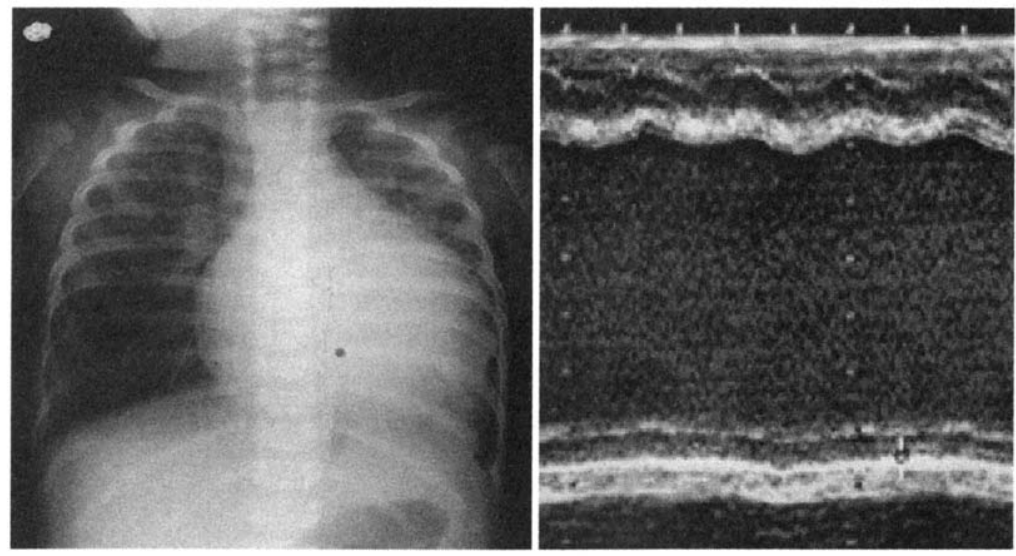

Fig 1. Preoperative chest $\mathrm{x}$-ray film and echocardiogram.
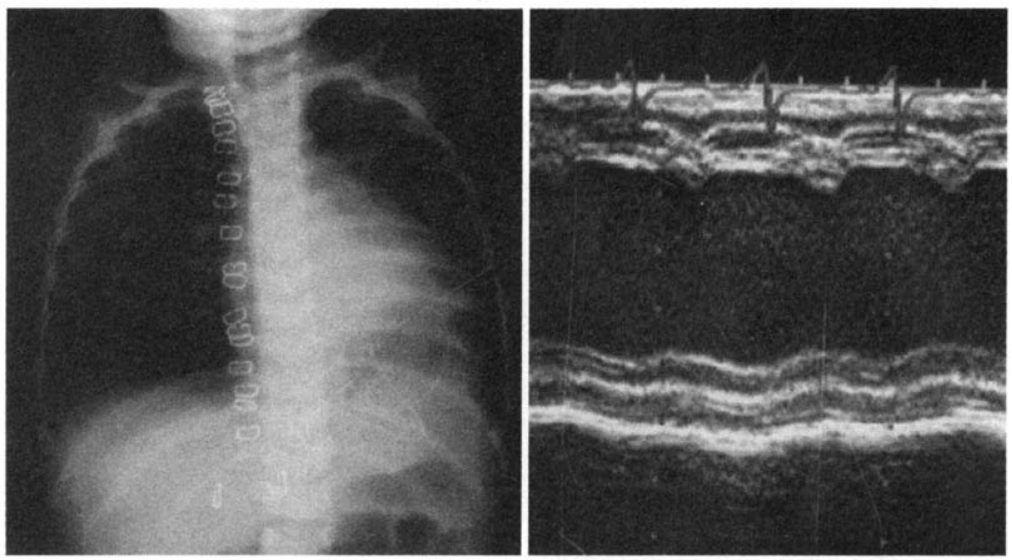

Fig 2. Postoperative chest x-ray film and echocardiogram.

tion was detected by intraoperative transesophageal echocardiography.

The initial $\mathrm{SvO}_{2}$ was $24 \%$ and a severe low-output syndrome was suspected. In the intensive care unit, the hemodynamics were maintained with dopamine, dobutamine, milrinone, and hydralazine. The $\mathrm{SvO}_{2}$ increased steadily. On the third postoperative day, the $\mathrm{SvO}_{2}$ was $60 \%$ to $70 \%$. On the fourth postoperative day, the $\mathrm{SvO}_{2}$ was $70 \%$. She was weaned from the respirator. Her general condition improved. After the first postoperative week, the diastolic dimension was 41.4 $\mathrm{mm}$, the systolic dimension was $37.6 \mathrm{~mm}$, the ejection fraction was $25 \%$, and the CTR was $57 \%$ (Fig 2). One month after the operation, $\beta$-blocker therapy was started. Her condition improved clinically.

Histopathologic examination revealed fibrous thickening of the endomyocardium, interstitial fibrosis, and perivascular fibrosis in the myocardium, consistent with DCM.

Comment. In Japan, heart transplantation in infants is not possible because of legal problems. Although Batista's operation is an option for severe DCM in adults, it is a palliative procedure that is in no way equal to heart transplantation. In our situation, partial left ventriculectomy has several advantages; the procedure can be performed on an elective basis, no donor is needed, and postoperative immunosuppressive therapy is not required.

Our patient was critically ill just before the operation. The following key points were considered before the procedure was attempted. Theoretically, this procedure results in improved left ventricular function in adults. We expected the same results. Clinically, many reports have been published concerning adults who have become well enough to be removed from the heart transplantation waiting list. Although resection of the left ventricle in an infant with DCM could be limited to the area between the two papillary muscles, it was determined that Alfieri's mitral repair could also be used to improve left ventricular function.

Our patient's condition improved clinically. Therefore partial left ventriculectomy should be considered for infants with DCM. 


\section{REFERENCES}

1. Batista RJV, Santos JLV, Takeshita N, Bocchino L, Lima PN, Cunha MA. Partial left ventriculectomy to improve left ventricular function in end-stage heart disease. J Card Surg 1996;11:96-7.

2. Batista RJV, Verde J, Nery P, Bochino L, Takeshita N, Bhayana JN, et al. Partial left ventriculectomy to treat end-stage heart disease. Ann Thorac Surg 1997;64:634-8.

3. McCarthy PM, Starling RC, Wong J, Scalia GM, Buda T, Vargo
RL, et al. Early results with partial left ventriculectomy. J Thorac Cardiovasc Surg 1997;114:755-65.

4. Chin TK, Perloff JK, Williams RG, Jue K, Mohrmann R. Isolated noncompaction of left ventricular myocardium: a study of eight cases. Circulation 1990;82:507-13.

5. Fazio S, Sabatini D, Capaldo B, Vigorito C, Giordano A, Guida $\mathrm{R}$, et al. A preliminary study of growth hormone in the treatment of dilated cardiomyopathy. N Engl J Med 1996;334:809-14.

\title{
CYTOLOGIC EXAMINATION OF SURGICAL MARGIN OF EXCISED MALIGNANT PULMONARY TUMOR: METHODS AND EARLY RESULTS
}

\author{
Noriyoshi Sawabata, MD, ${ }^{\mathrm{a}}$ Takashi Mori, MD, ${ }^{\mathrm{b}}$ Keiji Iuchi, MD, ${ }^{\mathrm{b}}$ Hajime Maeda, MD, ${ }^{\mathrm{a}}$ Mitsunori Ohta, MD, ${ }^{\mathrm{a}}$ and
} Osamu Kuwahara, MD, ${ }^{\text {a }}$ Osaka, Japan

Tumor excision is a strategy to treat peripheral pulmonary malignant lesions in high-risk candidates for lobectomy or pneumonectomy and in patients with metastatic tumors. ${ }^{1-3}$ Certain wedge-excised malignant tumors recur at the surgical margin despite histologic evidence of a safe margin. ${ }^{4}$ Even if the histologic examination reveals no evidence of malignancy on the margin of an excised tumor, this is no guarantee that the lung tissue around the excised margin is free from malignant cells, because histologic examination cannot study all aspects of the surgical margin of an excised tumor. Besides, cytologically, we can collect specimens from the whole area of the surgical margin of an excised malignant tumor. The purpose of this study is to demonstrate the method and the early results of cytologic examination on the surgical margins of wedge-excised tumors.

Technique. From April 1996 to May 1998, 35 small peripheral malignant pulmonary nodules (less than $3 \mathrm{~cm}$ in diameter) from 30 patients were excised. The patients, aged 50 to 82 years, included 24 men and 6 women. Seven lesions were subjected to video-assisted thoracoscopic surgery (VATS) and 28 to thoracotomy. Preoperative diagnoses were as follows: 8 undiagnosed lung cancers, 17 lung cancers, and 10 metastatic cancers from colorectal carcinoma.

Cytologic examination of the surgical margin was performed before the cross section was studied to prevent malignant cell contamination. Material for cytologic examination

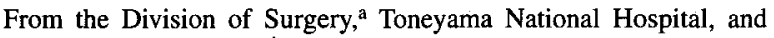
Division of Surgery, ${ }^{b}$ Kinki Central National Hospital for Chest Diseases, Osaka, Japan.

Received for publication Aug 19, 1998; accepted for publication Oct 14, 1998.

Address for reprints: Noriyoshi Sawabata, MD, Division of Surgery, Toneyama National Hospital, 5-1-1 Toneyama, Toyonaka, Osaka, Japan 560-8552.

J Thorac Cardiovasc Surg 1999;117:618-9

Copyright $(1999$ by Mosby, Inc.

$0022-5223 / 99 \$ 8.00+0 \quad \mathbf{1 2 / 5 4 / 9 5 2 9 9}$

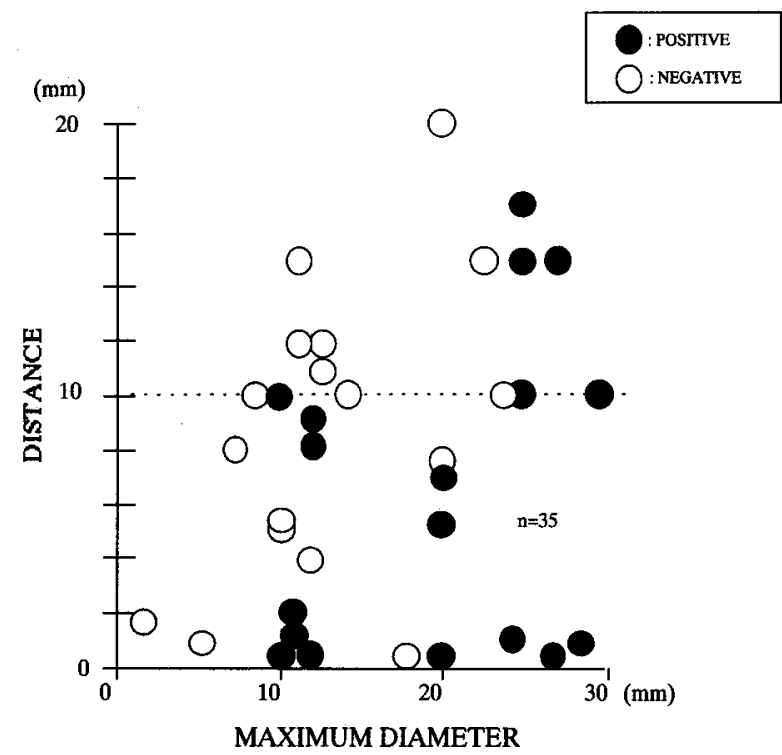

Fig 1. Cytologic diagnosis on surgical margins of wedgeresected malignant tumor. Among 15 samples showing histologically safe marginal distance (more than $10 \mathrm{~mm}$ ), $40 \%$ $(6 / 15)$ of them had cytologically positive surgical margins.

of the surgical margin of wedge-excised lung was harvested with a glass slide. The glass side was run across the staple site at least three times until sufficient material was collected. The harvested sample was spread on another glass slide and fixed by ethanol spray as soon as possible. It took approximately 15 seconds to harvest samples for cytologic examination and 12 minutes to apply the Papanicolaou stain. A cytopathologist was on site and interpreted the slide. After the materials for cytologic examination had been harvested, the wedge-resected specimen was cut and examined grossly and pathologically. Cytologic diagnoses of surgical margins of wedge-resected malignant tumors are described in Fig 1. Among 15 samples 